\title{
AS LUTAS NAS AULAS DE EDUCAÇÃO FÍSICA: O QUE ESTE CONTEXTO ESCOLAR NOS PROPÕE?
}

\author{
Vinicius Aparecido Galindo iD1, Jederson Garbin Tenório iD2, \\ Jean Aragão Ronsó da Costa Lima iD3
}

Resumo: Este trabalho tem como finalidade analisar os jogos como ferramenta no ensino das lutas nas aulas de Educação Física (EF). Diante da defasagem que se percebe desse conteúdo em boa parte das escolas brasileiras, acredita-se ser importante redimensionar o papel da luta como parte da própria cultura. A inserção das lutas no contexto escolar é fundamental no desenvolvimento cognitivo, social e motor dos alunos. A metodologia utilizada é o levantamento bibliográfico e documental, por meio de uma pesquisa qualitativa. Considera-se que as lutas devem ter uma aproximação com a prática da EF escolar podendo contribuir com uma visão renovada, além de apresentar aos alunos os conteúdos e os modos de abordar as lutas, por meio da ludicidade necessária para cada etapa de ensino.

Palavras-chave: Educação Física escolar; Lúdico; Cultura Corporal de Movimento.

\section{FIGHTS IN PHYSICAL EDUCATION CLASSES: WHAT DOES THIS SCHOOL CONTEXT PROPOSE?}

Abstract: This work aims at analyzing games as a tool in the teaching of fights in Physical Education (PE) classes. Due to the perceived gap in this content in most Brazilian schools, it is believed to be important to resize the role of fight as part of the culture itself. The insertion of fights in the school context is fundamental to cognitive, social, and motor development of students. The methodology used is the bibliographic and documentary survey, through qualitative research. It is considered that fights should have a better approximation with the practice of school PE and can contribute with a renewed vision, in addition to presenting students content and ways to approach the fights, through the playfulness necessary for each teaching stage.

Keywords: School Physical Education; Ludic; Body Movement Culture.

\footnotetext{
${ }^{1}$ Mestre em Ciências do Movimento Humano pela Universidade Metodista de Piracicaba. Professor do curso de Educação Física no Centro Universitário do Norte Paulista (UNORP) na cidade de São José do Rio Preto - SP. E-mail: viniciusgalindo@yahoo.com.br.

${ }^{2}$ Mestre em Ciências do Movimento Humano, pela Universidade Metodista de Piracicaba. Professor na rede de ensino de Mato Grosso, na cidade de Cláudia-MT. E-mail: jederson.21@hotmail.com.

${ }^{3}$ Graduado em Educação Física pelo Centro Universitário do Norte Paulista (UNORP). Professor de Caratê em projetos sociais na cidade de São José do Rio Preto -SP. E-mail: jean_shotokan1@hotmail.com.
} 


\section{Introdução}

As lutas são práticas corporais eminentemente culturais, provenientes de diferentes espaços, tempos históricos e pertencentes à denominada cultura corporal do movimento, que tem na educação do movimento, uma oportunidade de crítica à cultura dominante, vinculada à violência e à briga, sendo cauteloso sublinhar que:

No Brasil, a violência, sobretudo urbana, está no centro do dia a dia e ocupa as manchetes dos jornais. Ela é assunto de especiais para a tv e, mais que tudo, assombra as consciências, de tal forma é ameaçadora, recorrente e geradora de um profundo sentimento de insegurança. Essa evolução é sintoma de uma desintegração social, de um mal-estar coletivo e de um desregramento das instituições públicas (CHESNAIS, 1999, p. 53).

A EF, como disciplina que tem a especificidade de tratar de determinados temas, constitui área propícia para ressignificar saberes ligados ao senso-comum. As lutas, infelizmente, possuem alguns pré-conceitos negativos ligados à violência, agressividade, em uma perspectiva biológica, excludente, que foram barreiras, que impediam seu desenvolvimento na EF escolar, dentre outros elementos. Chesnais (1999, p. 59), comenta o que a televisão dissemina sobre a questão da violência:

Ora, a televisão faz, a cada dia, a apologia do dinheiro e da violência: os assassinos são apresentados como heróis dos tempos modernos. Há um monopólio dos produtores e uma ausência de controle dos consumidores, submetidos a uma enxurrada de imagens sangrentas.

A compreensão das lutas como uma prática corporal construída socialmente, reflete o modo como o sujeito está inserido nas sociedades, sendo de fundamental importância a observação de como as lutas são desenvolvidas no interior da escola.

A escola possui um estatuto e uma estrutura que se relaciona historicamente e socialmente com contexto na qual está inserida, estabelecendo relações pedagógicas e aprendizagens que fundamentam o currículo escolar, que de acordo com Libâneo (1994), o processo educativo é sempre contextualizado socialmente, havendo uma subordinação à sociedade que estabelece interesses de ordem política, econômica e cultural. Embora, seja importante frisar que as relações sociais não são estáticas e engessadas, ou seja, são dialógicas e muitas vezes, conflitantes, mesmo assim podem se mover para além de uma relação vertical, dependendo das possibilidades e necessidades cotidianas dos sujeitos. Mocarzel e Murad (2013), embora reconheçam que o conteúdo lutas é pouco desenvolvido nas escolas, compreendem que, a mídia também auxilia na difusão de adeptos à medida que divulga o desempenho de lutadores brasileiros, criando uma espécie de identidade maior com os sujeitos. "São exemplos desse pensamento: ter diversos campões internacionais em várias práticas marciais (como judô, taekwondo e kung-fu) [...]" (MOCARZEL e MURAD, 2013, p. 72). 
É um paradoxo perceber que esse conteúdo tão pouco difundido/problematizado nas escolas, é objeto de um número cada vez maior de praticantes em clubes e academias. Para Betti e Zuliani (2002), os adolescentes diminuem o interesse pela EF e começam a despertar curiosidade por outros assuntos, tais como, sexualidade, trabalho, vestibular. Por outro lado, ocorre uma gradativa procura dos alunos por outros espaços, tais como academias, clubes, parques, festas etc. (ZAGO e GALANTE, 2016).

Assim, a EF escolar, sendo uma prática social, poderá facilitar às crianças e aos adolescentes o acesso ao conhecimento sobre as práticas corporais (jogos, lutas, esportes, danças, ginásticas etc.), articulando-se com o contexto social acerca da realidade do ambiente escolar. Ou seja, deve-se, ainda, destacar que essas práticas corporais poderão ter como propósito o desenvolvimento de valores e de atitudes, o respeito e a valorização da cultura do outro, o autoconhecimento como manifestações que podem ser adotadas nos momentos de tempo disponível.

Silva (2016), valoriza o papel do professor que elabora brincadeiras e jogos a partir das lutas, possibilitando por meio do lúdico uma aprendizagem mais efetiva. O mesmo autor afirma que, na $E F$, as lutas possuem valores que expressam culturalmente e competências, sociais e cognitivas, melhorando a capacidade motora dos alunos. A necessidade de aplicabilidade das lutas no ambiente escolar passa evidentemente pela questão da formação de professores, porque eles são o principal canal de conexão de um novo olhar para as lutas com a prática pedagógica da Educação Básica, o que ocorre é, muitas vezes, o distanciamento entre os saberes profissionais dos professores e os conhecimentos universitários, o que provoca rupturas para a construção dos saberes (TARDIF, 2012). Significa dizer que, o fato de as lutas não serem potencializadas nas escolas, também é de responsabilidade dos cursos de nível superior.

Segundo Callai, Becker e Sawitzk (2019), sobre a prática pedagógica do professor:

Para se ter uma prática pedagógica consistente, se faz necessário um comprometimento ético, político e democrático, pois este processo está relacionado com a conduta de cada professor e a relação desse com os seus saberes, sejam eles adquiridos em sua formação inicial/continuada ou através de sua experiência (CALLAI; BECKER; SAWITZK,2019, p.6).

A necessidade de olhar para a experiência crítica da formação inicial dos professores, repensando a universidade e seu papel é indicado por Goergen (2014). O autor traz dimensões importantes para a reflexão sobre uma modificação nos caminhos da universidade: argumentar a favor de uma "consciência crítica" e a reflexão sobre o mundo e pelo mundo.

O pensamento crítico não objetiva construir pontes, curar pacientes ou inventar aparatos tecnológicos. Busca, sim, compreender o mundo, a sociedade e o ser humano; busca, portanto, valorizar o pensamento e a locução que transcendem os limites da validação empírico-operacional (GOERGEN, 2014, p. 572). 
Deve-se ir, então, além da instrumentalidade do ensino e da pesquisa, valorizando a formação de professores, que deve ir além do tecnicismo, do saber específico, devendo ser uma formação preocupada com o contexto, com a cultura, com a história: "O conhecimento técnico ou científico não substitui a reflexão intelectual, a formação cultural, luz indispensável para a atuação apropriada e segura da prática pedagógica" (GOERGEN, 2014, p. 577).

Sabe-se que valorizar o sujeito em seu contexto sociocultural no ambiente escolar promove a abertura para o diálogo e a reflexão entre as diferenças, favorecendo o acesso ao conhecimento e à informação. Além disso, possibilitar a partilha de atitudes e valores pode gerar uma aproximação e a troca de experiências entre as diferentes culturas. Acerca dos fatores restritivos para o ensino das lutas, Rufino e Darido (2015), consideram a formação deficiente, insegurança do professor, problemas de infraestrutura, vestimenta adequada, entre outros, atrapalham o professor de EF, principalmente aqueles sem muitos conhecimentos sobre lutas, o que resulta, muitas vezes, na ausência de abordagem dessas práticas.

A Base Nacional Comum Curricular (BNCC) surgiu como um novo documento ${ }^{4}$ norteador da EF, contemplando o conteúdo ${ }^{5}$ lutas, articulando-se com outras práticas corporais devendo ser desenvolvido conforme oito dimensões: experimentação, fruição, uso e apropriação, uso e reflexão, análise, compreensão e construção de valores, protagonismo comunitário. Em relação à aplicabilidade do conteúdo lutas a BNCC se refere como:

[...] disputas corporais, nas quais os participantes empregam técnicas, táticas e estratégias específicas para imobilizar, desequilibrar, atingir ou excluir o oponente de um determinado espaço, combinando ações de ataque e defesa dirigidas ao corpo do adversário (BRASIL, 2017, p. 176).

Um trabalho pedagógico com os educandos no âmbito das lutas na EF escolar, é de suma importância para que eles possam desenvolver uma aprendizagem significativa com o propósito de desenvolver a autonomia e o pensamento crítico diante desta temática dia após dia acerca da sua realidade. Isto é, com o intuito de ampliar seus conhecimentos por meio das lutas e suas relações sociais. E além disso, possibilitar aos sujeitos a compreensão dos elementos que caracterizam as lutas como as regras, técnicas, o uso de equipamentos e a adaptação dos diversos espaços sejam na escola, casa, dentre outros para tornar sua prática efetiva-ativa.

Segundo So e Betti (2018), o ensino de lutas no ambiente escolar encontra-se permeado por desafios e tensões, sendo necessária a

${ }^{4}$ A BNCC (BRASIL,2017), embora seja a diretriz pedagógica nacional da educação em vigor, que precede os Parâmetros curriculares nacionais "PCNs" (BRASIL,1999), é alvo de contundentes críticas por parte de estudiosos da área, como Betti (2018) e Neira (2018), por apresentar equívocos conceituais. Além disso, a BNCC, foi germinada em 2016, por meio de uma Medida Provisória (MP), editada pelo presidente Michel Temer, que demonstrava claramente a imposição de um documento ao campo educacional, sem a discussão dos atores envolvidos, com interesses vinculados à mecanismos internacionais de viés econômicos.

$5 \mathrm{Na}$ BNCC (2017), adota-se a terminologia de "conteúdos", para "unidades temáticas", inserindo as "práticas corporais de aventura" em relação ao documento dos PCN's. 
ressignificação dos preconceitos dos educandos, "[...] a (re)construção do conhecimento pedagógico deste conteúdo por parte do educador, e que a Educação Física como disciplina escolar deve inter-relacionar todas as figuras do aprender: saber-objeto, saber-domínio e saber-relacional" (SO e BETTI, p.555, 2018).

Muitas vezes, as lutas no ambiente escolar são deixadas de lado por alguns professores nas aulas de EF, pelo fato de terem uma ideia equivocada de que estas práticas corporais (lutas) são vivências que promovem agressividade ou violência. Essa crença pode ser decorrente de uma das tendências antigas da disciplina: a EF militarista, que tinha a meta de formar uma juventude para o combate, a luta e a guerra, mas, foi uma tendência que teve seu apogeu durante o período nazifascista. Hoje em dia, a inclusão das lutas na disciplina de EF, não tem pretexto de formar alunos-soldados, nem os preparar para a guerra (FERREIRA, 2006).

No sentido de ressignificar essa imagem distorcida das lutas e mostrar que é possível trabalhá-las com ludicidade e criatividade, o objetivo deste trabalho consiste em analisar e compreender o desenvolvimento dos jogos como conteúdo das lutas nas aulas de EF.

\section{Metodologia}

Neste trabalho, faz-se uso do levantamento e análise bibliográfica e documental. Segundo Severino (2007), as obras levantadas na pesquisa bibliográfica foram lidas e analisadas por meio da análise textual (pesquisar informações sobre o autor do texto, observar o vocabulário, estilo e método escrita), temática (buscou ouvir o autor e aprender, sem modificar o conteúdo da mensagem apresentada por ele), interpretativa (interpretar e compreender as ideias do autor) e crítica (elaboração do pensamento e se posicionando criticamente, problematizando o texto e contextualizando as ideias do autor). Já na pesquisa documental, realizou-se na sistematização de dados obtidos, os quais tiveram como referência documentos no sentido amplo, ou seja, não apenas documentos impressos, mas também a outros tipos de documento tais como: fotos, gravações, jornais, filmes, documentos legais etc. (SEVERINO, 2007).

De acordo com Fonseca (2002), foi realizada por meio da busca de referências teóricas já publicadas, em meios escritos e eletrônicos, como artigos científicos eletrônicos, livros, dentre outros materiais. Assim sendo, no desenvolvimento deste estudo, foram pesquisados artigos científicos e livros relacionados a temática deste estudo e que ajudassem no cumprimento do objetivo desta proposta. Numa pesquisa bibliográfica e documental utiliza-se essencialmente contribuições dos diversos autores sobre determinado assunto e a documental leva em conta que o primeiro passo é fundamentado na busca das fontes documentais. Para cumprir com tal objetivo, realizamos uma pesquisa qualitativa, "[...] que responde a questões muito particulares. Ela se preocupa, nas ciências sociais, com um nível de realidade que não pode ser quantificado. Ou seja, ela trabalha com o universo de significados, motivos, aspirações, crenças, valores e atitudes [...]". (MINAYO, 2001, p.21/22). 
O levantamento bibliográfico e documental foi realizado nos sistemas (base de dados): UNESP, UNICAMP, UNIMEP, UFRGS, no google acadêmico (livros, dissertações, teses e periódicos). Esta pesquisa bibliográfica e documental foi efetuada no período de dezembro de 2019 a abril de 2020, por meio de ferramentas disponíveis na internet a partir das obras relativas aos termos chave do trabalho, relacionados entre si (lutas, educação física escolar, lúdico e cultura corporal de movimento).

\section{Resultados e discussões}

\subsection{As lutas e o conceito de cultura na educação física escolar}

O tratamento que as práticas corporais recebem na contemporaneidade, bem como o interesse despertado por tais manifestações sociais, acaba por refletir na EF, como em nenhuma outra disciplina escolar.

Essa realidade é produto de um processo que se desenvolveu mundialmente pós-segunda guerra e que se tornou um lucrativo negócio, tendo como parceira fiel a EF escolar. Após a década de 1940, o fenômeno esportivo, sob influência europeia, foi incorporando-se em várias partes do mundo, como elemento predominante na cultura corporal de movimento. "O esporte sofre no período do pós-guerra um grande desenvolvimento quantitativo" (BRACHT, 1992, p. 22). Este mesmo autor comenta que posterior a esse período, na década de 1970, ocorre o "boom" na disseminação da indústria do fitness e da saúde, surgindo inúmeras academias de ginásticas e de artes marciais, ofertando diversas práticas corporais, desde aulas de dança, alongamento, artes marciais até ginástica aeróbica etc. Para complementar, segundo Furtado (2009), na década de 1980, o crescimento do mercado das academias, é impulsionado pela prática do fisiculturismo por meio de filmes que foram assistidos por milhões de pessoas ao redor do mundo, tornando as academias um negócio lucrativo.

Nesse contexto, as atividades físicas e esportivas tinham características bem definidas, ou seja, elevar o nível cardiorrespiratório, bem como melhorar o condicionamento físico dos praticantes. Esse movimento na área, mesmo que no ambiente extraescolar, teve influências no modo de desenvolver as aulas de $E F$, podendo ser visto e compreendido em diálogo com uma tendência esportivista ${ }^{6}$ em interface com 0 ensino tecnicista. 0 modelo esportivista visava à formação de atletas e a aptidão física, que conforme Maldonado e Silva (2016, p. 32): "A EF voltava-se para a construção de um corpo ordeiro, disciplinado, forte, conferindo saúde e aptidão física ao trabalhador, preparando-o para as exigências técnicas do trabalho".

Dessa maneira, se desenvolvia a EF na escola com características bem definidas, ou seja, alunos executores de exercícios físicos e práticas mecânicas.

\footnotetext{
${ }^{6}$ Para González e Fensterseifer (2005), a esportivização pode ser compreendida como produto de transformação de práticas corporais originadas em contextos não competitivos e não institucionalizados que se converteram em modalidades esportivas, assumindo os códigos e rituais do esporte de rendimento.
} 
É aí que reside a necessidade de problematizarmos os dilemas a serem esclarecidos acerca da inserção metodológica não só das lutas, mas de outros conteúdos pertencentes à EF. Com a abertura política e social na década de 1980 , vários professores de EF tiveram suas pesquisas e estudos realizados no viés das ciências humanas, propondo um novo olhar à prática metodológica, que se moveu no sentido de tencionar o modelo até então hegemônico voltado à vertente biológica.

Surgiram após esse período, perspectivas pedagógicas com um entendimento de que a EF deveria inserir os alunos na esfera da cultura corporal de movimento, considerando a diversidade de sujeitos que adentram a escola, conforme suas expectativas, experiências, educação familiar etc.

Muitas dessas discussões foram contempladas na construção dos Parâmetros Curriculares Nacionais (PCN's), (BRASIL, 1999) e das Diretrizes Curriculares Nacionais (DCN's), (BRASIL, 2010), documentos norteadores da educação básica, embora, posteriormente, a disciplina de EF, na BNCC foi tratada com retrocessos, conforme a visão de Bungenstab e Lazzaroti Filho (2017), que nos alertavam para a possibilidade de sofrer com a entrada de profissionais com o "reconhecido" notório saber, com a inclusão da formação técnica e profissional no currículo. Segundo os autores supracitados: "Neste EM que se desenha há um forte indício que a EF passe a se apresentar por meio de uma visão atlética e esportivizante da vida" (BUNGENSTAB e LAZZAROTI FILHO, 2017, p.37). Tais considerações caminham paralelamente nesse período embora, exista uma expectativa de resistência dos educadores, em função de uma formação contemplada com a contribuição de disciplinas da Filosofia, da Sociologia e da Didática, nos últimos trinta anos.

Obviamente é preciso reconhecer os pontos que favorecem a difusão e adesão de praticantes de atividade física dentro e fora da escola. Os meios de comunicação, embora transmitam uma certa mensagem que necessita ser analisada criticamente, há que se perceber a linguagem televisiva tem a capacidade de sensibilizar o espectador. "A imagem da televisão, provoca, inicialmente, um impacto emocional, que comove, envolve todos os nossos sentidos, arrepia, faz rir ou chorar e, nessa fase, não adiante apelar à razão, por que a imagem não se dirige ao intelecto" (BETTI, 2013, p. 221).

Pode-se destacar que incentivado pelos meios de comunicação e pelas instituições esportivas, denota o "estímulo" para que crianças e adolescentes imitem gestos e movimentos de ídolos, que representa uma autoridade, que tem prestígio sobre as pessoas. Esse processo é denominado por Mauss (2003) de imitação prestigiosa.

O que se passa é uma imitação prestigiosa. A criança, como o adulto, imita atos bem-sucedidos que ela viu ser efetuados por pessoas nas quais confia e que têm autoridade sobre ela. $O$ ato se impõe de fora, do alto, mesmo um ato exclusivamente biológico, relativo ao corpo. 0 indivíduo assimila a série dos movimentos de que é composto o ato executado diante dele ou com ele pelos outros. É precisamente nessa noção de prestígio da pessoa que faz o ato ordenado, autorizado, provado, em relação ao indivíduo imitador, que se verifica todo o elemento social (MAUSS, 2003, p. 405). 
No contexto particular das lutas, essa ressignificação possivelmente, estabeleça um diálogo com as figuras de lutadores como, Aurélio Miguel, Acelino Popó de Freitas, Anderson Silva, José Aldo, dentre outros, tendo implicações nesse processo, inclusive na adoção de práticas corporais em academias e clubes. Segundo Mocarzel e Murad (2013, p. 70): "Foi em virtude dos eventos transmitidos pela mídia que as práticas marciais ganharam enorme destaque no mundo e principalmente no Brasil, pelo fato de 0 campeão ter sido um brasileiro: Royce Gracie". Para os autores, ao se referirem à década de 1990, a constatação de que a mídia tenha elementos que favoreçam o incentivo de alunos à prática de atividades físicas, é um ponto a ser valorizado.

Mesmo assim, considera-se as práticas corporais veiculadas pela mídia, associadas a um discurso extremamente positivo, ou seja, obscurecem-se os competidores que não conseguem vencer. O destaque é focado no sujeito que consegue se sobressair tecnicamente, em detrimento da esmagadora maioria dos participantes, que inclusive são parte do processo e sem eles, não haveria o campeão, ocorrendo isso no esporte, na dança, na ginástica e nas lutas.

Trazendo a realidade para o "chão da quadra", é preciso estar atento para que a aula EF não se oriente predominantemente pelos signos de uma prática de alto rendimento, pois não possui sentido de coletividade, sociabilidade e diálogo, se reduzindo à cópia de um modelo pronto, configurando-se em uma ação motora mecânica, que objetiva a execução de um movimento, sem possibilitar ao aluno uma aprendizagem crítica, apropriando-se do conhecimento.

A formação inicial e o contato com disciplinas ligadas à didática e metodologias de ensino, poderão auxiliar o professor a ressignificar e dar um tratamento pedagógico aos diversos conteúdos, diferenciando-os de alguns entendimentos do senso-comum. Do ponto de vista biológico, o corpo tido como uma construção exclusivamente natural e considera-se normal que, por exemplo, os alunos mais altos joguem basquete com mais facilidade, os magrinhos praticarem futsal com maior destreza, as meninas a dançarem com certa leveza e os gordinhos a arremessar peso em uma distância maior. Nessa direção, Daolio (2006, p.27), complementa esse argumento, com as seguintes palavras: "O raciocínio é simples: se o corpo é um conjunto de ossos, músculos e articulações, todos os corpos são iguais, por possuírem os mesmos componentes. Portanto, a mesma atividade serve para todos os alunos em quais lugar e época".

A EF escolar calcada em pressupostos culturais (Daolio, 2006), tem a finalidade de revisão de valores de modelos tecnicistas e mecanicistas, propondo uma educação que seja e esteja sensível às diferenças existentes entre os alunos e se preocupe em inseri-los dentro do contexto das aulas, oportunizando e ampliando suas vivências de práticas corporais.

Segundo Eagleton (2005), a raiz latina da palavra cultura é "colere" que significa cultivar e habitar até prestar culto e proteger. "Colere" é, também, originária da expressão latina "cultus", termo religioso "culto", e que a própria ideia, na era moderna, é substituída por um evanescente conceito de divindade e transcendência. 
Neste trabalho, partimos do princípio de que é preciso ressignificar as lutas e a sua relação com a violência e vinculá-la às práticas culturais. Entender as lutas enquanto manifestações culturais implicam em considerar seu potencial enquanto manifestação dos sujeitos no discurso de sua representação social, na mesma ótica da definição conceitual de Geertz (2012) a respeito da cultura:

[...] é essencialmente semiótico. Acreditando, como Max Weber, que o homem é um animal amarrado a teias de significados que ele mesmo teceu, assumo a cultura como sendo essas teias e a sua análise; portanto, não como uma ciência experimental em busca de leis, mas como uma ciência interpretativa, à procura do significado (GEERTZ, 2012, p.4).

Já que a cultura é resultado de uma construção do homem, este autor afirma que: "A cultura, esse documento de atuação, é, portanto, pública [...]. Embora uma ideação, não existe na cabeça de alguém; embora não física, não é uma identidade oculta" (GEERTZ, 2012, p.8).

As lutas são conteúdos da cultura corporal, ou seja, utilizam a linguagem corporal como forma de expressão do corpo e reproduzem saberes construídos na história (SOARES et al.,1992). Isto é, as lutas são manifestações culturais acumuladas historicamente pela sociedade devem ser valorizadas no contexto escolar adaptando o conteúdo com o intuito de disseminar os saberes corporais e culturais para os estudantes nas aulas de EF. Rufino e Darido (2015, p. 22) defendem a característica histórica e cultural das lutas fundamentando que "[...] são práticas historicamente importantes e que acompanharam os seres humanos ao longo do tempo, sendo umas das mais elementares manifestações [da] cultura".

Betti e Zuliani (2002) entendem e consideram perceptível que a tradição educacional do nosso país tenha situado a EF como uma atividade complementar e relativamente isolada nos currículos das escolas, com objetivos determinados, muitas vezes, de fora para dentro, como treinamento pré-militar, preparação de atletas, eugenia, nacionalismo, dentre outros. Mas os autores afirmam também que essa concepção hoje não se aplica, tendo em vista a ascensão da cultura corporal e esportiva. O que ajudou para que tal ascensão acontecesse foi à difusão dos meios de comunicação em massa sobre a cultura corporal do movimento.

No entanto, é preciso um esforço para que a cultura corporal do movimento seja explorada em sua diversidade, pois as novas condições socioeconômicas, como a informatização, automatização do trabalho, degradação dos espaços públicos de lazer e a violência, leva um grande número de sujeitos a um estilo de vida sedentário, à alimentação inadequada, ao estresse, dentre outros problemas. Um deles é o excesso de horas diante da televisão ou, mais recentemente, do celular ou computador, o que: "especialmente por parte das crianças e adolescentes, diminui a atividade motora, leva ao abandono da cultura de jogos infantis e favorece a substituição da experiência de praticar esporte" (BETTI; ZULIANI, 2002, p.74). 
Nota-se que a baixa presença do conteúdo lutas no ambiente escolar é uma realidade como relatam Nascimento e Almeida (2007), quando questionados sobre qual a razão, na pesquisa realizada pelos discentes do curso de EF da UNIJUÍ, os educadores investigados indicam duas justificativas centrais para a ausência dos conteúdos lutas (práticas corporais) nas aulas de EF: a) falta de experiência sobre a temática seja na formação acadêmica do curso (graduação) em EF ou em suas histórias de vida; e b) a violência seria intrínseca às lutas, e sua prática corporal estimularia a agressividade dos educandos.

Se as lutas forem vistas como conteúdo passível de aprendizagem na perspectiva cultural é possível modificar o olhar das lutas pela escola, ampliando a ideia de que somente alguns conteúdos fazem parte das possibilidades da EF escolar. Essa ideia se reforça nas práticas escolares, quando os professores apenas dão a possibilidade de jogar futebol, ou seja, tendo em uma visão reducionista da realidade sobre as práticas da cultura corporal de movimento. Assim, é preciso estimular, através das lutas, a diversidade de práticas da cultura corporal de movimento (NASCIMENTO e ALMEIDA, 2007).

Neste sentido, cabe a nós professores de EF oportunizar aos alunos o acesso aos conhecimentos no ambiente escolar por meio do processo de aprendizagem das práticas corporais, que respeitem às diferenças entre si mesmos, promovendo o diálogo e a reflexão entre as diferentes culturas, buscando a socialização ao criar uma atmosfera positiva e saudável entre os sujeitos. A respeito disto, Cruz de Oliveira (2007), nos estabelece a necessidade acerca de evitarmos certos pensamentos reducionistas:

Um professor de EF [...] ao chegar numa escola e detectar que os alunos gostam e valorizam a prática do futebol, pode, no discurso da consideração da realidade dos alunos, acabar "moldando" toda sua ação em torno de uma única prática corporal, tolhendo assim, inúmeras outras possibilidades de acesso ao conhecimento (CRUZ DE OLIVEIRA, 2007, p.24).

É importante refletir sobre o sujeito de forma heterogênea por meio da diversidade cultural, valorizando o diferente como recurso fundamental para compreender sua cultura. Assim sendo, não devemos pensar o ser humano de uma forma única, deve-se refletir nessa diversidade sobre as ações culturais humanas, ou seja, as interações entre as pessoas. Para Pinto (1992, p. 292):

A educação física precisa compreender, construir, avançando conhecimentos sobre a essência orgânica e cultural das diferentes linguagens do corpo, que se manifestam de várias formas [...]. É importante identificar e compreender as estruturas e significados das diferentes manifestações da cultura corporal de movimentos, esforçando-se por compreender seus sentidos e importância para a vida do ser e para as suas relações culturais, historicamente estabelecidas.

$\mathrm{Na}$ atualidade, espera-se que o professor nas aulas de EF desenvolva os diversos tipos de conteúdo (jogos, brincadeiras, lutas, danças, ginásticas etc.) para os alunos, visando a construção da autonomia, da criatividade e da 
criticidade. Além disso, que possa potencializar aos educandos uma educação de qualidade, valorizando sua bagagem cultural, e que seu aprendizado tenha sentido e significado, por meio de atividades diversificadas no ambiente escolar.

\subsection{Por que ensinar as lutas na escola?}

Segundo Lopes e Pontes (2019), a prática da luta está relacionada a sobrevivência humana. Antigamente, para garantir a sua subsistência, o ser humano precisava correr, saltar, lutar e realizar diversas atividades dia após dia. Assim sendo, as lutas trazem na sua essência, uma filosofia de vida, o autocontrole, o respeito ao próximo, a disciplina, dentre outros valores. Nos dias atuais, as lutas fazem parte do rol de eixos temáticos ou conteúdos em documentos norteadores da área de EF. Além disso, estão inseridas em diversos contextos sociais tais como: esportes (de combate), nos treinamentos de segurança pública, privada ou militar, nas academias e são também praticadas como atividade complementar nos espaços escolares. As lutas devem ser ensinadas na escola, pois, segundo Oliveira (2009, p.169):

A motricidade das lutas e confrontos simbólicos e físicos que são proporcionados nas Artes Marciais, quando direcionados e estruturados por uma filosofia, melhora o autoconhecimento e assim contribuem positivamente no aspecto emocional do praticante, evitando situações de descontrole que possam tornar-se negativas.

É possível que insegurança e dúvidas apareçam quando o tema lutas é abordado como conteúdo nas aulas de EF. Surgem equívocos devido à vinculação desse conteúdo ao favorecimento dos alunos se tornarem mais agressivos e violentos. Assim, as lutas são constituídas como uma temática das aulas de EF que encontram uma grande resistência pelos educadores, ocorrendo preconceitos em relação ao seu ensino. De acordo com Matos et al. (2015), os preconceitos estão relacionados às questões de violência, roupa e materiais adequados. Rufino e Darido (2015, p. 57) comentam que "[...] os preconceitos estão cristalizados, o que torna ainda mais difícil significá-los. Nesses casos, será necessário 'lutar' para quebrar determinados paradigmas que possam prejudicar o ensino das lutas na escola".

Oliveira (2009), reconhece as críticas à forma como se usa ou se prática as expressões da cultura corporal na escola e afirma que espera que o professor de EF consiga superar as dificuldades naturais que surgem ao se usar as práticas de luta nesse ambiente, de maneira que se faça uma adaptação à tradição (modelos e paradigmas) das lutas ao mundo atual e as necessidades da escola. Gonçalves e Graça (2016), comentam que os conteúdos de lutas não se trabalham somente em combates ou técnicas, mas rico em valores morais e éticos e que as tendências críticas são fundamentais para uma reflexão sobre os mesmos.

Del Vecchio e Franchini (2006) sugerem a abordagem do ensino das lutas propiciem aos alunos uma aprendizagem alinhada as dimensões de conteúdo nos aspectos: conceituais, procedimentais e atitudinais que os 
auxiliem a análise crítica e criativa desta prática corporal, compreendendo os processos didáticos e assimilando conteúdos que os possibilitem aprender e ensinar. Assim sendo, na dimensão conceitual do ensino das lutas, podem ser relacionados os aspectos conceituais sobre a variedade de modalidades existentes, as regras (normas) de determinadas modalidades, a apreciação das modalidades que fazem parte dos jogos olímpicos ou as que não fazem e o processo histórico sobre diferentes modalidades. Já a dimensão procedimental está relacionada ao saber fazer dos movimentos individuais ou em dupla realizados na prática das lutas em uma perspectiva lúdica na realização de jogos ou brincadeiras relacionadas a temática das lutas etc. E na dimensão atitudinal no que tange às atitudes, normas e valores que devem ser desenvolvidos em relação às lutas, os princípios éticos e orientadores como a cooperação, a justiça, o respeito mútuo, dentre outros. Ou seja, embora as dimensões de conteúdo sejam organizadas em três, nas experiências práticas do processo de aprendizagem, elas devem estar articuladas umas às outras, sendo inadequado o ensino das lutas por meio de cada dimensão de forma separada. Assim, socializando-se entre si, promovem uma visão ampla dos conteúdos, favorecendo a aprendizagem de tais práticas. Ao contrário, com o ensino fragmentado, tem-se um sentido diferente daquilo que é proposto (RUFINO; DARIDO, 2013).

So e Betti (2018), afirmam que apesar da inclusão formal das lutas na legislação, através dos currículos oficiais de vários estados e municípios, 0 ensino de lutas no ambiente escolar ainda encontra- se em um campo de tensões que mais potencializa sua exclusão do que inclusão no campo da EF escolar. Em sua pesquisa de campo realizada em uma escola da periferia de Bauru/SP, com alunos do $7^{\circ}$ ano, identificaram que o entendimento inicial dos alunos era de que as lutas são violentas, relacionadas ao gênero masculino e promotoras de danos físicos, ou seja, havia um imaginário negativo dos educandos sobre as lutas. Dessa maneira, foi modificada esta visão pelo ingresso a uma comunidade de pessoas que reconheceram nas lutas um espaço de expressão corporal e cultural. Observa-se que a imagem negativa das lutas não é apenas por parte do professor, mas também dos alunos, por isso, é fundamental mostrar que essa é uma imagem que não condiz com as lutas, para isso, é preciso que elas estejam no dia após dia nas escolas brasileiras.

Rufino (2016), por sua vez, considera que as lutas devam ser tematizadas de maneira criativa e crítica por meio da compreensão de sua lógica interna, isto é, das características que as diferenciam das demais práticas corporais, enfatizando o olhar para uma visão ampla da realidade, além da compreensão de modalidades de luta. Essa é uma ótica que, para o autor, auxilia na compreensão de que o educador não precisa ser especialista em uma ou outra modalidade para disseminar o aprendizado de lutas no ambiente escolar. Este mesmo autor considera evidente a necessidade de se aprofundar mais os estudos no âmbito das lutas enquanto manifestações corporais e como elas podem favorecer o processo de compreensão e leitura de mundo a partir da visão de cultura corporal. A seguir, apresentamos possibilidades de ensino, por meio de jogos, para o conteúdo lutas na EF. 


\subsection{Os jogos lúdicos por meio do conteúdo lutas nas aulas de educação física}

Sobre o lúdico, como Pedon (2014), consideramos como um componente da cultura historicamente acumulada, como produto e como processo, como conteúdo e como forma.

Antunes (2003), afirma que existe um abismo entre o brincar e o aprender, considerando que muitas pesquisas acadêmicas demonstram que ambos estão relacionados, sendo possível desenvolver competências pedagógicas por meio de atividades diversificadas na escola.

Através das lutas, por exemplo, o professor mostra ao aluno, que se pode aprender de forma mais prazerosa e lúdica. Quando isso acontece o conhecimento não é esquecido, pois o conhecimento que se adquire por meio de uma aprendizagem significativa é absorvido e lembrado por mais tempo, ampliando a capacidade de aprender outros conteúdos com mais qualidade (PELIZZARI et al., 2002). Ou seja, as atividades lúdicas são muito propícias às aulas de EF, devendo estar presentes também nessa disciplina de maneira elaborada, com objetivos claros, precisos.

Ferreira (2008), esclarece que há as pequenas lutas diretas, indiretas, livres, combinadas e com "armas" (acessórios) que podem ser aplicadas na escola com a finalidade pedagógica. Diretas são aquelas atividades lúdicas de lutas onde o contato corporal permanece durante toda a atividade, como: empurrar o parceiro para fora de um círculo adaptado (sumo); empurrar e puxar seu parceiro em linha reta (trator); tentar pisar, em duplas, nos pés do parceiro e/ou bexiga (balão inflável) sem perder o contato das mãos (esgrima com os pés). As indiretas correspondem às atividades lúdicas de lutas nas quais o contato corporal é pequeno ou inexistente, por exemplo: cabo de guerra; em duplas, tentar tocar os joelhos do companheiro; jogo de imobilização. As lutas livres são as atividades lúdicas de lutas em que os movimentos são executados sem o confronto com um parceiro, como soco e chutes na bexiga (balão inflável); chutes e socos em jornais; quedas e rolamentos; katas (são movimentos formais com um ou dois adversários imaginários). As lutas combinadas são as atividades lúdicas de lutas nas quais podem ocorrer à combinação das lutas diretas, indiretas e livres. Exemplos: tentar "roubar a bola" no chão; luta ajoelhada; sequência chutar, agarrar e derrubar. Por fim, as pequenas lutas com "armas" são atividades lúdicas de lutas que utilizam objetos adaptados das lutas como instrumento pedagógico, como bastão de madeira e/ou alternativo; nunchaku de jornal e espada de jornal (FERREIRA, 2008).

Em um trabalho sobre as brincadeiras de luta, Farias Wiggers e Viana (2014) afirmam que elas contribuam na educação do corpo, tirando ansiedades e medos. Assim, tiros com pistolas d'água, brigas de travesseiro, lutinhas (combates) de mentirinha revelam riscos que contribuiriam para distinguir a fantasia e a imaginação da realidade, permitindo que os alunos representem universos imaginários através do corpo e do movimento, (re) construídos a partir de variadas influências interativas. 
No sentido de colaborar com estudos sobre as possibilidades de atividades envolvendo lutas distribuídas de acordo com as etapas do ensino básico, Ferreira (2006) apresenta propostas para diferentes etapas:

Na educação infantil, as lutas de animais (luta do sapo, luta do jacaré ou a luta do saci) têm ajudado muito na liberação de agressividade das crianças, além de serem trabalhados, nestas atividades, todos os fatores psicomotores. No ensino fundamental, lutas que requerem um maior esforço trazem excelentes respostas, como a luta do "empurra e puxa" ou o "uga-uga" (tirar o colega de dentro do círculo central). No ensino médio, as modalidades começam a ser exploradas de uma maneira mais profunda, levando ao conhecimento do tema, fazendo um resgate histórico das modalidades e as relacionando com a ética e os valores (FERREIRA, 2006, p.37).

Para que promovam práticas na escola, como exemplificadas acima, é preciso que os professores tenham uma formação adequada e do esforço individual de buscar uma formação continuada para explorar e ressignificar a luta na escola. Farias, Wiggers e Viana (2014) compreendem que a criança vivencie ativamente o jogo social, fundamentado por (re) construções de identidade incorporadas dia após dia, seja na rua, no apartamento, em casa, na escola, outros espaços ou em frente da televisão ou do computador. Assim, as brincadeiras de lutas identificadas na escola assumiriam perspectivas diferentes, promovendo elementos acerca de papeis sociais de gênero, do imaginário infantil e das interlocuções entre as mídias, além da exposição da diferença entre o lúdico e a violência.

Segundo Breda et al (2010), é relevante destacar a classificação das Lutas em elementos de curta distância (espaço próximo de um sujeito ao outro, exemplos deste tipo de lutas: judô, sumô, jiu-jitsu), de média distância (espaço moderado que permite uma aproximação em situações de ataque entre os adversários, exemplos deste tipo de luta: boxe, taekwondo, caratê, muay thai) e de longa distância (utiliza-se um implemento na dinâmica da luta, tais como: arma, bastão ou outro recurso/acessório, exemplos deste tipo de luta: esgrima, kendo, kung fu). Matos et al. (2015, p. 124) comentam que as classificações das Lutas "[...] permitem ao professor melhor sistematizar seu planejamento no sentido de abordar as Lutas partindo de seus princípios operacionais, envolvendo, desta forma, muitas modalidades diferentes, mas com características semelhantes". Isto é, estas classificações possibilitam ao educador sistematizar seu planejamento com o intuito de fundamentar o conteúdo das lutas a partir de seus princípios operacionais, envolvendo, deste modo, muitas modalidades diferentes, porém com características semelhantes.

É importante destacar que as atividades em espaços diferenciados da escola, como a quadra de esportes, devem ser mediadas pelo professor, de modo articulado e planejado, pois, as atividades lúdicas são meios que contribuem e enriquecem o desenvolvimento intelectual, motor e social dos educandos. Menin (2016) falam que o jogo oferece ao educando a vivência das situações-problemas, que permitam o toque às experiências com a lógica e o raciocínio e, nas atividades físicas e mentais, favorecendo a sociabilidade, 
estimulando as reações cognitivas, afetivas, morais, culturais, linguísticas e sociais.

Freire (1996, p. 17), comenta que a curiosidade ingênua se criticiza, tornando-se então, metodicamente na sua aproximação do objeto, um ponto indicador de maior exatidão. Assim, espera-se que os alunos despertem a criticidade sobre os jogos e brincadeiras aplicados, promovendo um esclarecimento dos problemas do dia a dia.

Nessa linha de raciocínio acerca da necessidade de trabalhar com o lúdico, Pedon (2014), afirma em seu trabalho, que o ensino do karatê, baseado em jogos e brincadeiras é uma maneira de proporcionar aos alunos a diversão, desenvolvimento pessoal e viabilizar aos mesmos o acesso ao conhecimento dessa luta e a construção de importantes valores, como companheirismo, noção do coletivo e respeito. Quando o ensino do Karatê ocorre a partir de jogos e brincadeiras, o mesmo autor relata que é possível transformar a mecanização dos movimentos em algo divertido e significativo.

No percurso de desenvolvimento de sua pesquisa, Pedon (2014), observou que as aulas tradicionais de Karatê desestimulavam os alunos praticantes, porque todo início de ano as vagas eram preenchidas, e após certo período, os alunos desistiam, o que chamou a atenção para a necessidade de utilizar novas metodologias, buscando incentivar a permanência dos alunos nas vivencias durante o ano todo. Embora esse espaço (turma de Karatê de um colégio particular), nos auxilia a pensar a ludicidade deve permear o processo de aprendizagem, mantendo os participantes estimulados por um maior tempo possível.

O jogo, segundo Huizinga (2010), é uma categoria primária da vida, tão importante quando a fabricação de objetos e o raciocínio, isso significa que o elemento lúdico está no início do surgimento e do progresso cultural da civilização. Este mesmo autor, sintetiza as principais características do jogo, fundamentando-o como "[...] uma atividade livre, conscientemente tomada como não-séria e exterior à vida habitual, mas ao mesmo tempo capaz de absorver o participante de maneira intensa e total" (HUIZINGA, 2010, p. 16). Ou seja, é uma atividade em que não se visa nenhum interesse lucrativo, e, nela, o sujeito é compreendido por uma visão ampla, respeitando uma ordem e certas regras ou normas, características da ação, o que promove a interação entre diferentes culturas. Assim, é importante que os jogos estejam associados ao ensino das lutas, dando um tratamento pedagógico diferenciado em seu aprendizado.

Inicialmente, Pedon (2014), realizou um contato inicial com os alunos (que tinham entre 9 e 12 anos) para saber qual seria o propósito na prática do karatê. Descobriu-se que eles consideravam as aulas com movimentos repetitivos e eram muito exaustivas. A partir dessa constatação, buscou-se elaborar novas estratégias para ensinar o karatê de forma mais atrativa, buscando novos estímulos e diminuindo a evasão nas aulas. No relato da intervenção, o autor afirma que observou as brincadeiras que tinham um significado para aqueles alunos, em seguida foi possível fazer a escolha e adaptar as brincadeiras para as aulas de Karatê. Trazemos abaixo a descrição pelo autor de uma atividade elaborada a partir dessa união entre o lúdico e o 
Karatê. A brincadeira de "polícia e ladrão" (variação do jogo de pegar e de esconder, em que um grupo procura o outro pelo espaço de jogo, com o intuito de prender seus integrantes) é muito interessante e possível de ser adaptada para as aulas de Karatê. Com os participantes divididos em dois grupos - a polícia e a dos ladrões - a atividade é desenvolvida com a busca dos ladrões escondidos pelo espaço de jogo, por parte do grupo dos que ficaram como policiais. O grupo de ladrões deve dificultar ao máximo que sejam capturados, fugindo quando possível. Nesse momento, a atividade é desenvolvida como um jogo de pegador, isto é, quando um fugitivo é pego, ao toque do pegador, ele deve parar e ser levado até a área inicial de jogo. Nessa área os ladrões capturados (pegos) devem fazer uma corrente, de mãos dadas. Se um dos ladrões não capturados tocar em alguém da corrente, os presos serão soltos e novamente poderão fugir. No término do jogo, os grupos invertem os papéis. Vence o grupo que capturar o maior número de ladrões ao final de cada tempo ou a que capturar todos os ladrões em menor tempo de jogo (PEDON, 2014).

Os recursos necessários para realizar essa brincadeira são um espaço aberto, amplo e não há limite de faixa etária, desde que os sujeitos tenham capacidade de deslocamento pelo espaço, para evitarem de se machucarem. Orienta-se que a atividade seja desenvolvida com grupos de pessoas de faixa etária e capacidades físicas semelhantes.

Ao adaptar-se para a prática do Karatê, Pedon (2014) explica que a diferença é que quando o ladrão fosse pego na prisão, o educando deveria fazer um kata (apresentação de golpe de qualquer faixa de graduação). Caso o (a) aluno (a) fosse pego (a) uma vez, executaria o kata de sua faixa, se fosse pego duas vezes, deveria realizar o kata de sua faixa e mais um outro kata. Após cumprir com essas tarefas, poderia sair da "prisão". No caso de o educando ainda não saber executar o kata, o educador ou um aluno mais graduado ficaria na prisão ensinando-o, até que ele pudesse aprender e conseguisse realizar o movimento de forma adequada, para depois, retornar ao jogo.

Este mesmo autor analisa que a estratégia foi positiva, inclusive, relata que notou que os alunos começaram a fazer o kata fora das aulas de karatê, para que no momento da brincadeira pudessem executá-lo e voltar a brincar o mais rápido possível. Através dessa pesquisa realizada neste espaço (turma de Karatê de um colégio particular) onde os alunos estudam no período regular no período da manhã e à tarde, logo após as aulas participam da arte marcial escolhida foi possível descobrir uma nova prática pedagógica, utilizando jogos e brincadeiras como norteadores das aulas de Karatê.

Nascimento e Almeida (2007), relatam uma experiência de intervenção numa turma de $4^{a}$ série ( $5^{\circ}$ ano) do ensino fundamental (séries iniciais), que apresentava um grau elevado de dificuldade para manejar suas emoções, o que estava gerando comportamentos violentos, físicos e a verbalização de palavras inadequadas, principalmente quando as práticas desenvolvidas envolviam competição coletiva. O propósito foi de levar as lutas, buscando construir coletivamente sua prática e possibilitando a socialização entre os alunos, de uma maneira diversificada dos jogos coletivos com bola, ou seja, a lógica comporta a oposição e colaboração, para ofertar a experiência da 
oposição com contato corporal característico das lutas. Na primeira aula, por exemplo, desenvolveu-se a leitura do texto denominado "Brincando de Lutar" (tratava de conhecimentos sócio-históricos a respeito das lutas), que envolvia o desenvolvimento sobre as manifestações de luta e exploração conceitual da lógica das distintas lutas. Utilizou-se inicialmente um texto seguido de debate e visualização por meio de um vídeo relacionado a temática lutas diferenciadas entre si. Na atividade, houve a participação efetiva de todos os alunos, além da expectativa inicial, o interesse se manteve durante a aula. Para a aula seguinte, solicitou-se a tarefa de pensar sobre questões estruturais de uma luta para ser vivenciada, de acordo com os critérios prévios repassados quanto ao objetivo estabelecido, as ações proibidas e as ações permitidas (NASCIMENTO \& ALMEIDA, 2007).

A intervenção ocorreu em mais sete aulas e, ao final, os autores notaram que não houve manifestação de comportamentos agressivos, nem física, nem verbalmente, na realização de todas as aulas, contrariamente, perceberam um comprometimento constante nas tomadas de decisões e um cuidado para o cumprimento dos acordos. Essa é uma conclusão importante para aqueles que não consideram levar as lutas para a escola por medo da violência que poderia resultar dessa atitude. Dessa maneira, concluem que: "Precisamos elaborar 'novas' abordagens a partir de nossas experiências práticas" (NASCIMENTO \& ALMEIDA, 2007, p.108).

Portanto, cabe ao educador se qualificar continuamente e viabilizar suas ações pedagógicas com seus alunos em condições de igualdade que poderão acrescentar intelectualmente e culturalmente ao sujeito, promovendo atividades diversificadas e articuladas ao seu contexto social na qual a instituição escolar está inserida e alinhada ao processo de ensinoaprendizagem em todas as esferas humanas.

\section{Considerações finais}

Conforme os apontamentos deste estudo, a ludicidade presente nas lutas permite que os alunos enxerguem nas aulas de EF novos modos de aprender, para além do tradicional futebol. As brincadeiras que passam regras e conteúdo das lutas na Educação Básica deveria ser uma estratégia fundamental a ser utilizada pelos professores na escola. Além disso, valorizar o contexto histórico-cultural (lutas), utilizando o jogo como principal estratégia de ensino-aprendizagem, pautando-se no diálogo, na reflexão e na compreensão das regras e posturas (condutas) dos sujeitos antes, durante e após as aulas, refletindo-se no cotidiano dia após dia no ambiente social.

Sobre as intervenções didáticas pelo professor no ensino de lutas no ambiente escolar o propósito é realizar um trabalho numa perspectiva construtivista, ou seja, buscar os dados da realidade e além disso, observando as manifestações de cultura de movimento dos alunos nas aulas de EF. Logo após este momento, fazer um planejamento para introduzir o conteúdo de lutas nas aulas de EF e desenvolver atividades no tocante das lutas analisando as insuficiências e os acertos obtidos por meio das atividades propostas, considerando-se a valorização do conhecimento prévio do educando e as 
expectativas de ensino-aprendizagem previamente definidas. Sumarizando, após as ações pedagógicas realizadas compete ao professor de Educação Física observar se as ações didáticas realizadas colaboraram para desenvolver o repertório de conhecimentos dos educandos sobre as práticas corporais trabalhadas nas lutas e se os objetivos foram atingidos.

Considerar a escola como local de construção do saber promove o acesso as diversas culturas produzidas pelos alunos possibilitando 0 desenvolvimento de suas potencialidades. Ou seja, para que o processo educativo seja construído com sentido e significado, é essencial que as ações humanas sejam valorizadas e estejam alinhadas acerca da realidade dos educandos, promovendo a eles um conhecimento, através da reflexão e da prática, de analisar, interpretar, compreender e criticar os elementos da cultura corporal de movimento (brincadeiras, jogos, lutas, atividades rítmicas, esportes, dentre outros). Assim, os elementos da cultura corporal de movimento serão tratados como conhecimentos a serem ressignificados pelos sujeitos ampliando a construção do conhecimento na instituição de ensino.

Além disso, a formação e qualificação dos professores deve englobar o conteúdo das lutas na escola, de uma maneira mais frequente, diversificando as aulas e dando uma nova dimensão, desmistificando o preconceito sobre as lutas. Através das lutas vimos que os alunos desenvolvem habilidades, são estimulados a se conhecer, seguir regras, se comunicar. Portanto, as lutas constituem fatores importantes que contribuem para o desenvolvimento das capacidades físicas, motoras e cognitivas dos alunos além da filosofia (essência) que a luta propicia.

É fundamental que os professores compreendam a importância de incorporar as lutas no contexto escolar, com atividades lúdicas, pois assim o processo de assimilação é facilitado, transformando a realidade em conhecimento, tornando parte significativa do aprendizado. A temática desenvolvida nesta pesquisa necessita de outras contribuições por se tratar de um problema contínuo e recorrente no ambiente escolar e na dinâmica social dia após dia.

\section{REFERÊNCIAS}

ANTUNES, Celso. O jogo e a educação infantil: falar e dizer, olhar e ver, escutar e ouvir. Vozes, 2003.

BETTI, Mauro. A versão final da Base Nacional Comum Curricular da Educação Física (ensino fundamental): menos virtudes, os mesmos defeitos. Rev. Bras. Educ. Fís. Escolar, 2018. Disponível em:

file:///D:/Usuario/Downloads/BETTIBNCCRebescolar.pdf. Acesso em: 12 jun. 2020.

BETTI, Mauro. Entre Assistir e Praticar: Educação Física, Esporte, Televisão e Lazer. In: MARCELLINO, Nelson Carvalho (Org.) Lúdico, educação e educação física. Ijuí: Ed. Unijuí, 2013. p. 217-232. 
BETTI, Mauro; ZULIANI, Luiz Roberto. Educação Física escolar: uma proposta de diretrizes pedagógicas. Revista Mackenzie de Educação Física e Esporte, ano 1, número 1, 2002.

BUNGENSTAB, Gabriel Carcalho; LAZZAROTTI FILHO, Ari. A Educação Física no "novo" Ensino Médio: a ascensão do notório saber e o retorno da visão atlética e "esportivizante" da vida. Motrivivência, 2017. Disponível em:

file:///D:/Usuario/Downloads/50199-177404-1-PB.pdf . Acesso em: 10 mai. 2020.

BRASIL. Ministério da Educação. Base Nacional Comum Curricular. Brasília: MEC, 2017. Disponível em: http://basenacionalcomum.mec.gov.br/abase/ . Acesso em: 15 mai. 2020.

BRASIL. Ministério da Educação. Secretaria de Educação Básica. Diretrizes Curriculares Nacionais para o Ensino Fundamental. Brasília: MEC, SEB, 2010.

BRASIL. Ministério de Educação e do Desporto. Parâmetros Curriculares Nacionais: Ensino Médio/ Secretaria de Ensino Médio. Brasília: MEC/SEM, 1999.

BRACHT, Valter. Educação Física e Aprendizagem social. Porto Alegre: Magister, 1992.

BREDA, Mauro; GALLATI, Larissa Rafaela; SCAGLIA, Alcides José; PAES, Roberto Rodrigues. Pedagogia do esporte aplicada às lutas. São Paulo: Phorte, 2010.

CALLAI, Ana Nathalia Almeida; BECKER, Eriques Piccolo; SAWITZK, Rosalvo Luis. Considerações acerca da Educação Física escolar a partir da BNCC.

Conexões: Educação Física, Esporte e Saúde, Campinas, v. 17, p.1-16, mar., 2019. Disponível em:

https://periodicos.sbu.unicamp.br/ojs/index.php/conexoes/article/view/86547 39/21555. Acesso em: 17 mai. 2020.

CHESNAIS, Jean Claude. A Violência no Brasil. Causas e recomendações políticas para a sua prevenção. Ciência \& Saúde Coletiva, v. 4, n.1, p. 5369, 1999.

CRUZ de OLIVEIRA, Rogério. Educação Física e diversidade cultural: um diálogo possível. Conexões: revista da Faculdade de Educação Física da Unicamp, 2007. Disponível em:

https://periodicos.sbu.unicamp.br/ojs/index.php/conexoes/article/view/86378 76/5567. Acesso em: 18 jun. 2020. 
DAOLIO, Jocimar. Cultura: educação física e futebol. 3a. Ed. Campinas: Editora da Unicamp, 2006.

DEL VECCHIO, Fabricio Boscolo; FRANCHINI, Emerson. Lutas, artes marciais e esportes de combate: possibilidades, experiências e abordagens no currículo da educação física. In: SOUZA NETO, Samuel; HUNGER, Dagmar. (Org.). Formação profissional em educação física: estudos e pesquisas. Rio Claro: Biblioética, 2006. p. 99-108.

EAGLETON, Terry. A Ideia de Cultura. Trad. Sandra Castello Branco. São Paulo: Unesp, 2005.

FARIAS, Mayrhon José Abrantes; WIGGERS, Ingrid Dittrich; VIANA, Raimundo Nonato. O Lúdico e a violência nas brincadeiras de luta: um estudo do "se movimentar" das crianças em uma escola pública de São Luís, Maranhão Brasil, HOLOS, 2014. Disponível em:

http://www2.ifrn.edu.br/ojs/index.php/HOLOS/article/viewFile/2543/939. Acesso em: 10 jun. 2020.

FERREIRA, Heraldo Simões. As lutas na Educação Física escolar. Revista de Educação Física, n. 135, nov., p.36-44, 2006.

FERREIRA, Eduardo. Apostila didática de lutas. Piracicaba: Unimep, 2008.

FONSECA, João José Saraiva. Metodologia da pesquisa científica. Fortaleza: UEC, 2002.

FREIRE, Paulo. Pedagogia da autonomia: saberes necessários à prática educativa. São Paulo: Paz e Terra, 1996.

FURTADO, Roberto Pereira. Do Fitness ao Wellness: os três estágios de desenvolvimento das academias de ginástica. Pensar a Prática, v. 12, n. 1, 12 mar., p.1-11, 2009.

GEERTZ, Clifford. A interpretação das culturas. Rio de Janeiro: LTC, 2012.

GOERGEN, Pedro. Tecnociência, pensamento e formação na Educação Superior. Revista Avaliação, 2014. Disponível em:

https://www.scielo.br/pdf/aval/v19n3/03.pdf . Acesso em: 15 jun. 2020.

GONÇALVES, Ramon Lucio; GRAÇA, Rômulo Luiz. As lutas na escola: possibilidades e concepções pedagógicas. Trabalho de Conclusão de Curso, Faculdade de Educação Física. Universidade do Extremo Sul Catarinense, UNESC, 2016. 
GONZÁLEZ, Fernando Jaime. Esportivização. In: GONZÁLEZ, Fernando Jaime; FENSTERSEIFER, Paulo Evaldo (Orgs.). Dicionário crítico de educação física. Ijuí: Ed. Unijuí, 2005.

HUIZINGA, Johan. Homo Ludens: o jogo como elemento da cultura. 6a. Ed. São Paulo: Perspectiva, 2010.

LIBÂNEO, José Carlos. Didática. São Paulo: Cortez, 1994.

LOPES, Rafael Rodrigues; PONTES, João Airton de Matos. A prática das lutas por escolares de uma instituição pública em Fortaleza. Revista Educação em Debate, Fortaleza, ano 41, n. 78, p.33-48, jan./abr. 2019. Disponível em: http://repositorio.ufc.br/handle/riufc/44216. Acesso em: 12 jan. 2021.

MALDONADO, Daniel Teixeira; SILVA, Sheila Aparecida Pereira dos Santos. Educação pública: a realidade da educação física na escola. Campinas: Mercado de Letras, 2016.

MATOS, José Arlen Beltrão; HIRAMA, Leopoldo Katsuki; GALATTI, Larissa Rafaela; MONTAGNER, Paulo Cesar. Presença/ausência do conteúdo lutas na educação física escolar: identificando desafios e propondo sugestões.

Conexões: Educação Física, Esporte e Saúde, Campinas, v. 13, n. 2, p. 11735, 2015. Disponível em:

https://periodicos.sbu.unicamp.br/ojs/index.php/conexoes/article/view/86406 58. Acesso em: 12 jan. 2020.

MAUSS, Marcel. Sociologia e antropologia. São Paulo: Cosac, 2003.

MENIN, Rosângela. Os benefícios dos jogos e brincadeira para educandos da educação de jovens e adultos. Produções didáticos-pedagógicas.

Secretaria de Estado da Educação do Paraná: Curitiba, 2016.

MINAYO, Maria Cecília de Souza. Pesquisa Social: Teoria, método e criatividade. 18a. Ed. Petrópolis: Vozes, 2001.

MOCARZEL, Rafael Carvalho da Silva; MURAD, Mauricio. O não uso das lutas na educação física escolar brasileira. In: OSBORNE, Renata; SILVA, Carlos Alberto Figueiredo; SANTOS, Roberto Ferreira dos (Orgs.). Complexidade da educação física escolar: questões atuais e desafios para o futuro. Rio de Janeiro: Lamparina, 2013.

NASCIMENTO, Paulo Rogério Barbosa do; ALMEIDA, Luciano de. A tematização das lutas na Educação Física escolar: restrições e possibilidades. Revista Movimento, 2007. Disponível em: https://seer.ufrgs.br/Movimento/article/view/3567/1968. Acesso em: 30 abr. 2020. 
NEIRA, Marcos Garcia. Incoerências e inconsistências da BNCC de Educação Física. Revista Brasileira de Ciências do Esporte, 2018. Disponível em: https://www.scielo.br/pdf/rbce/v40n3/0101-3289-rbce-40-03-0215.pdf . Acesso em: 04 jul. 2020.

OLIVEIRA, André Luis de. Jogos/brincadeiras de lutas: as culturas corporais de lutas na formação de professores de educação física. In: Anais de Eventos da Sociedade de Pesquisa Qualitativa em Motricidade Humana, IV Colóquio de Pesquisa Qualitativa em Motricidade Humana, 2009. Disponível em: http://www.motricidades.org/conference/index.php/cpqmh/4cpqmh/paper/vie wFile/155/58. Acesso em: 29 abr. 2020.

PEDON, Ivo. O ensino do Karatê por meio de jogos e brincadeiras: uma perspectiva cultural. Dissertação Pós-graduação em Educação Física Piracicaba, SP: [s.n.], 2014.

PELIZZARI, Adriana; KRIEGL, Maria de Lurdes; BARON, Márcia Pirib; FINCK, Nelcy Teresinha Lubi; DOROCINSK, Solange Inês. Teoria da aprendizagem significativa segundo Ausubel. Rev. PEC, Curitiba, v.2, n.1, p.37-42, jul., 2002.

PINTO, Leila Mirtes Santos Magalhães. A Recriação/ Lazer no "jogo" da Educação Física e dos Esportes. Revista Brasileira de Ciências do Esporte, Campinas, v.12, n.1, 2,3, p. 289-293, 1992.

RUFINO, Luiz Gustavo Bonatto; DARIDO, Suraya Cristina. Possíveis diálogos entre a Educação Física escolar e o conteúdo das lutas na perspectiva da cultura corporal. Revista Conexões. Campinas, v. 11, n.1, p.145-170, jan./mar. 2013. Disponível em: https://periodicos. sbu.unicamp.br/ojs/index.php/conexoes/article/view/8637635/5326. Acesso em: 10 jan. 2021.

RUFINO, Luiz Gustavo Bonatto; DARIDO, Suraya Cristina. O ensino das lutas nas aulas de Educação Física: análise da prática pedagógica à luz de especialistas. Rev. Educ. Fís/UEM, 2015. Disponível em: https://www.scielo.br/pdf/refuem/v26n4/1983-3083-refuem-26-04-00505.pdf . Acesso em: 10 jun. 2020.

RUFINO, Luiz Gustavo Bonatto; DARIDO, Suraya Cristina. O ensino das lutas na escola: possibilidades para a educação física. Porto Alegre: Penso, 2015.

RUFINO, Luiz Gustavo Bonatto. Os Jogos de lutas nas aulas de Educação Física escolar: possibilidades técnico-táticas e seus elementos invariantes. Revista Brasileira de Prescrição e Fisiologia do Exercício, 2016. Disponível em: http://www.rbpfex.com.br/index.php/rbpfex/article/view/1224/872 . Acesso em: 15 jun. 2020. 
SEVERINO, Antônio Joaquim. Metodologia do trabalho científico. $21^{a}$. Ed. São Paulo: Cortez, 2007.

SILVA, Everton Ibraim. As lutas como recurso pedagógico nas aulas de educação física. Acadêmico $8^{a}$ fase Licenciatura em Educação Física da Universidade do Extremo do Sul Catarinense - UNESC, 2016. Disponível em: http://repositorio.unesc.net/bitstream/1/4279/3/Everton\%20Ibraim\%20Silva.p df. Acesso em: 29 abr. 2020.

SOARES, Carmen Lúcia; Taffarel, Celi Nelza Zulke; Varjal, Elizabeth; Filho, Lino Castelani; Escobar, Micheli Ortega; Bracht, Valter. Metodologia de ensino de educação física. $2^{a}$. Ed. São Paulo: Cortez, 2012.

SO, Marcos Roberto; BETTI, Mauro. Sentido, mobilização e aprendizagem: as relações dos alunos com os saberes das lutas nas aulas de Educação Física. Movimento, 2018. Disponível em: https://seer.ufrgs.br/Movimento/article/view/70995/48684 . Acesso em: 30 jun. 2020.

TARDIF, Maurice. Saberes docentese formação profissional. Petrópolis: Vozes, 2012.

ZAGO, Nathalia; GALANTE, Regiane Cristina. Educação Física no Ensino Médio: concepções e reflexões. Ufscar, 2016. Disponível em:

http://www.eefe.ufscar.br/upload/10. Acesso em: 12 abr. 2020.

Recebido em: 24 de setembro de 2020.

Aceito em: 4 de janeiro de 2021x. Publicado em: 15 de dezembro de 2021. 